\begin{abstract}
Iranica
Abstracta Iranica Revue bibliographique pour le domaine irano-aryen

Volume 34-35-36 | 2017

Comptes rendus des publications de 2011-2013
\end{abstract}

\title{
Javier Álvarez-Mon, Mark B. Garrison (eds.). Elam and Persia
}

\section{Astrid Nunn}

\section{OpenEdition}

1 Journals

\section{Édition électronique}

URL : http://journals.openedition.org/abstractairanica/41417

DOI : 10.4000/abstractairanica.41417

ISSN : 1961-960X

Éditeur :

CNRS (UMR 7528 Mondes iraniens et indiens), Éditions de l'IFRI

\section{Référence électronique}

Astrid Nunn, « Javier Álvarez-Mon, Mark B. Garrison (eds.). Elam and Persia », Abstracta Iranica [En ligne], Volume 34-35-36 | 2017, document 2, mis en ligne le 15 juillet 2016, consulté le 28 septembre 2020. URL : http://journals.openedition.org/abstractairanica/41417 ; DOI : https://doi.org/10.4000/ abstractairanica.41417

Ce document a été généré automatiquement le 28 septembre 2020.

Tous droits réservés 


\title{
Javier Álvarez-Mon, Mark B. Garrison (eds.). Elam and Persia
}

\author{
Astrid Nunn
}

\section{RÉFÉRENCE}

Javier Álvarez-Mon, Mark B. Garrison (eds.). Elam and Persia. Winona Lake, Eisenbrauns, 2011, 493 p. et nb. ill. dans les articles archéologiques.

1 La conception de ce livre remonte à une rencontre des American Schools of Oriental Research à Philadelphie, lors de laquelle deux sessions avaient été dédiées à l'archéologie iranienne et en particulier à la relation entre l'Elam néo-élamite d'après la conquête assyrienne env. 647 av. J.-C. et la culture "perse" émergente au début de l'époque achéménide. Dans ce volume sont rassemblées 14 contributions ; il est divisé en trois sections basées sur l'archéologie (D. T. Potts, "The limits of Anšan » et E. Carter, "Landscapes of Death in Susiana»), sur l'analyse de textes (G. P. Basello, «L'élamite en tant que langue administrative », W. Henkelman, « Parnakka's Feast », E. Quintana, «Le règne d'Anšan», J. Tavernier, «Les Iraniens dans les textes néoélamites », M. Waters, " Parsumaš, Anšan et Cyrus ») et enfin sur le monde des images. C'est à cette partie qu'appartiennent les articles de Javier Álvarez-Mon, M. B. Garrison, Y. Hassanzadeh - H. Mollasalehi, M. Cool Root et D. Stronach (rub. 3.2.2, c.r. n 3, 4, 5, 6, 7).

2 Il n'y a pas de consensus sur de nombreux aspects de la fin de l'art élamite et du début de l'art perse. Même si le lecteur est dans ce volume confronté à différentes opinions, il en ressort néanmoins un "main body of evidence" pour le matériel philologique et archéologique. Le résultat de ces différentes études est une prise de conscience de plus en plus vive du fait qu'il existait une identité élamite indépendante de l'identité perse, tout spécialement dans le Fars du VI ${ }^{\mathrm{e}} \mathrm{s}$. Un second enseignement est que l'on peut effectivement parler de début de l'art perse à la fin du VII ${ }^{\mathrm{e}}$ s., ce que Pierre Amiet, à qui le livre est dédié, avait noté dès 1973. Pour lui en effet, le corpus des sceaux-cylindres 
néo-élamites représentait "l'ultime manifestation de la civilisation élamite tout comme la première manifestation de l'art perse”.

\section{AUTEURS}

\section{ASTRID NUNN}

Université de Munich 